\title{
NOTAS SOBRE O PAPEL DA EDUCAÇÃO NA OBRA DE LENIN ${ }^{1}$
}

\author{
Ricardo Adriano de Andrade ${ }^{2}$
}

\section{RESUMO:}

Neste trabalho apresentamos um debate acerca do papel da educação na compreensão e superação do modo de produção capitalista. Para tanto, foram elencadas duas questões: porque deve se estudar o modo de produção capitalista, se fundamentado no método fundado por Marx e Engels, e formalizado por Lenin - o materialismo dialético da história? E de que se trata a educação comunista? Assim foram revisados obras de Lenin acerca do modo de produção capitalista e do papel da educação comunista para classe trabalhadora. Finalmente, nos posicionamos no sentido de afirmar que a educação comunista trata-se da apropriação e desenvolvimento, fundamentados no materialismo dialético da história, da soma dos conhecimentos adquiridos pela humanidade sob o jugo do capitalismo a serviço da classe trabalhadora.

Palavras-chave: Modo de Produção Capitalista. Materialismo Dialético da História. Educação Comunista. Lenin.

\section{NOTES ON THE ROLE OF EDUCATION IN THE WORK OF LENIN}

\section{ABSTRACT:}

This paper presents a discussion about the role of education in understanding and overcoming of the capitalist mode of production. For both it was listed two questions: why they should study the capitalist mode of production, based on the method established by Marx and Engels, and formalized by Lenin - the dialectical materialism of the story? And what is it about education communist? So we reviewed the works of Lenin about the capitalist mode of production and the role of communist education for the working class. Finally, we stand to affirm that the communist education it is the ownership and development, based on dialectical materialism in history, the sum of knowledge gained by mankind under the yoke of capitalism to serve the working class.

Keywords: Capitalist Mode of Production. Dialectical Materialism of history. Communist Education. Lenin.

\section{Introdução}

O presente trabalho propicia o debate acerca da questão da educação como meio principal para que a classe trabalhadora aproprie a sua história, compreenda as contradições do capital e conduza a luta de classes para revolucionar da sua existência.

$\mathrm{O}$ objetivo em pauta refere-se responder duas questões principais: (I) porque deve se estudar o modo de produção capitalista, se fundamentado no método fundado por Marx e Engels, e formalizado por Lenin - o materialismo dialético da história? E (II) de que se trata a educação comunista?

Para este feito, foram revisadas obras de Vladimir Ilitch Lenin - ou seja, uma revisão de caráter bibliográfico - que discutem sobre o modo de produção capitalista, a educação comunista, e o papel da classe trabalhadora na revolução comunista. 
A justificativa em relação a escolha e seleção do trabalho de Lenin se deu ao fato de (i) uma incipiência de trabalhos voltados a discutir sua obra no tocante a educação brasileira $^{3}$ e, conseqüentemente, (ii) a necessidade de repetir suas investigações extremamente relevantes para compreensão do que se trata educação sob a balizas do marxismo-leninismo e seu papel na emancipação econômica e intelectual da classe trabalhadora.

Assim foram desenvolvidas discussões sobre o modo de produção capitalista na sua fase monopolista - o imperialismo - suas implicações para classe trabalhadora. Concomitantemente, foram confrontadas as questões relevantes ao Estado e revolução comunista. Neste contexto, o marxismo-leninismo é apontado com método primordial como guia para debater as contradições do capital e suprimi-lo.

Em seguida, são apontados e debatidos alguns fundamentos da educação comunista e o seu papel na revolução.

O estudo finaliza-se, esquadrinhando a relevância da educação comunista para classe proletária, a necessidade desta se apropriar da produção científica, filosófica, econômica, social e política da humanidade, balizada pelo método materialista dialética da história.

Assim sendo, a conclusão deste debate afirma que é preciso compreender o modo de produção capitalista para poder superá-lo, e somente o conjunto da obra de Marx, Engels e Lenin, e demais intérpretes, permite aos trabalhadores e trabalhadoras - somente a classe dos trabalhadores -, a se unirem, organizarem e realizar a edificação de outro modo de produção: o modo de produção comunista da existência.

\section{Modo produção capitalista da existência e o marxismo}

Para transformar a realidade é preciso partir da própria realidade, é necessário confrontá-la com finalidades distintas da própria realidade.

Partindo desta perspectiva, se baseando no estudo, na investigação, no trabalho de Lenin, no conjunto de sua obra, temos total clareza que produzimos nossa existência no e sob o ambiente do modo de produção capitalista em sua fase monopolista - o imperialismo.

Lenin, na perspectiva de diferenciar capitalismo monopolista do capitalismo do século XIX - amplamente investigado por Marx e Engels - infere que

O imperialismo surgiu como desenvolvimento e continuação direta das características fundamentais do capitalismo em geral. Mas o capitalismo só se transformou em imperialismo capitalista quando chegou a um determinado grau, muito elevado, do seu desenvolvimento, quando algumas das características fundamentais do capitalismo começaram a transformar-se na sua antítese, quando ganharam corpo e se manifestaram em toda a linha os traços da época de transição do capitalismo para uma estrutura econômica e social mais elevada. $\mathrm{O}$ que há de fundamental neste processo, do ponto de vista econômico, é a substituição da livre concorrência capitalista pelos monopólios capitalistas. A livre concorrência é a característica fundamental do capitalismo e da produção mercantil em geral; o monopólio é precisamente o contrário da livre concorrência, mas esta começou a transformar-se diante dos nossos olhos em monopólio, criando a grande produção, eliminando a pequena, substituindo a grande produção por outra ainda maior, e concentrando a produção e o capital a tal ponto que do seu seio surgiu e surge o monopólio: os cartéis, os sindicatos, os trusts ${ }^{4}$ e, fundindo-se com eles, o capital de uma escassa dezena de bancos que manipulam milhares de 
milhões. Ao mesmo tempo, os monopólios, que derivam da livre concorrência, não a eliminam, mas existem acima e ao lado dela, engendrando assim contradições, fricções e conflitos particularmente agudos e intensos. O monopólio é a transição do capitalismo para um regime superior.

[...] o imperialismo é a fase monopolista do capitalismo. Essa definição compreenderia o principal pois, por um lado, o capital financeiro é o capital bancário de alguns grandes bancos monopolistas fundido com o capital das associações monopolistas de industriais, e, por outro lado, a partilha do mundo é a transição da política colonial que se estende sem obstáculos às regiões ainda não apropriadas por nenhuma potência capitalista para a política colonial de posse monopolista dos territórios do globo já inteiramente repartido (LENIN, 2002, p.67).

Tal modo de produção, segundo o autor, se expressa, de forma geral, em cincos traços fundantes:(i) a concentração da produção e do capital levada a um grau tão elevado de desenvolvimento que criou os monopólios, os quais desempenham um papel decisivo na vida econômica; (ii) a fusão do capital bancário com o capital industrial e a criação, baseada nesse "capital financeiro" da oligarquia financeira; (iii) a exportação de capitais, diferentemente da exportação de mercadorias, adquire uma importância particularmente grande; (iv) a formação de associações internacionais monopolistas de capitalistas, que partilham o mundo entre si, e (v) o termo da partilha territorial do mundo entre as potências capitalistas mais importantes (LENIN, 2002, p. 67-68).

O revolucionário ainda completa seu raciocínio propondo que o imperialismo é o capitalismo na fase de desenvolvimento em que ganhou corpo a dominação dos monopólios e do capital financeiro, adquiriu marcada importância a exportação de capitais, começou a partilha do mundo pelos trusts internacionais e terminou a partilha de todo o planeta entre os países capitalistas dominantes.

Desta forma, a fase histórica que nos situamos esta demarcada por um elevado grau de desenvolvimento da concentração da produção, uma posse monopolista das fontes mais importantes de matérias-primas, uma apropriação centralizada do capital financeiro nas mãos dos bancos e o acirramento da luta por territórios econômicos - circunscrita desde os pactos coloniais.

O imperialismo - a fase monopolista do capitalismo, capitalismo de transição ou capitalismo agonizante - esta permeado por monopólios, oligarquias, pela exploração cada vez maior dos países subdesenvolvidos (por exemplo, o Haiti) ou em desenvolvimento (Brasil) por um punhado de nações riquíssimas ou mais fortes (aliás, uma nação, os Estados Unidos da América) - ou seja, uma perspectiva para a dominação capitalista parasitária ao invés de uma perspectiva libertária ou emancipatória.

Nada mais justo e indispensável, dizer que a revolução, e precisamente a revolução comunista, proletária é o movimento transformador, gerado pelas contradições do capitalismo, que pode superá-lo e concomitantemente edificar uma sociedade sem classes, uma sociedade comunista.

A questão da Revolução Comunista esta integralmente conectada a questão do Estado. Não é possível discutir a revolução sem discutir o poder do Estado. O próprio Lenin (1983, p. 7) já reivindica que a questão do Estado assume, em nossos dias (escrito no século XX com validade no século XXI), particular importância, tanto do ponto de vista teórico como do ponto de vista política prática. A guerra imperialista acelerou e avivou ao mais alto grau o processo de transformação do capitalismo monopolizador em capitalismo monopolizador de Estado. A monstruosa escravização dos trabalhadores pelo Estado, que 
se une cada vez mais estreitamente aos onipotentes sindicatos capitalistas, atinge proporções cada vez maiores. A revolução proletária universal está em maturação e a questão das suas relações com o Estado adquire, praticamente, um caráter de atualidade.

Nesta perspectiva, o autor supracitado, revisando as investigações de Marx e Engels e a experiência da Comuna de Paris de $1871^{5}$, propicia o debate no tocante as condições econômicas, políticas e sociais necessárias para a classe trabalhadora tomar e destruir a máquina do Estado - essa perspectiva é essencial para revolução comunista.

A idéia fundamental é que o Estado é produto e manifestação dos antagonismos de classes. O Estado aparece onde e na medida em que os antagonismos de classes não podem objetivamente ser conciliados. E, reciprocamente, a existência do Estado prova que as contradições de classes são inconciliáveis (LENIN, 1983, p. 12).

Para Engels, o Estado é um produto da sociedade numa certa fase do seu desenvolvimento. É a confissão de que essa sociedade se embaraçou numa insolúvel contradição interna, se dividiu em antagonismos inconciliáveis de que não pode desvencilhar-se. Entretanto, para que essas classes antagônicas, com interesses econômicos contrários, não se entre devorassem e não devorassem a sociedade numa luta estéril, sentiu-se a necessidade de uma força que se colocasse aparentemente acima da sociedade, com o fim de atenuar o conflito nos limites da "ordem" (LENIN, 1983, p. 12).

Já, de acordo com Marx (LENIN, 1983, p. 12), o Estado é um órgão de dominação de classe, um órgão de submissão de uma classe por outra; é a criação de uma "ordem" que legalize e consolide essa submissão, amortecendo a colisão das classes.

De fato, a revolução da classe trabalhadora, proletária deve tomar o Estado e destruí-lo, dar-lhe outra forma, uma forma transitória, provisória, passageira para que, segundo expressão do próprio Lenin, definhe.

Lenin (1983, p. 19), advoga que a primeira etapa da revolução dos trabalhadores e trabalhadoras é a constituição do trabalhador como classe dominante. É preciso implantar a ditadura do proletariado, a apropriação do Estado concebendo-o como classe trabalhadora organizada de forma dominante.

O autor supracitado, ainda acrescenta que os trabalhadores urbanos e rurais só têm a necessidade de um Estado em definhamento, que definhe do início ao fim. Concomitantemente, o Estado é necessário para que classe trabalhadora quebre a resistência dos exploradores - grandes capitalistas dos setores latifundiário, industrial e financeiro - e somente a classe trabalhadora tem envergadura para tal feito, pois a classe trabalhadora é a única que pode unir e organizar todos os trabalhadores na luta contra a burguesia, contra os capitalistas (LENIN, 1983, p. 19)

A experiência da Comuna de Paris em 1871, confirmou esse fato - somente a classe trabalhadora tem condições efetivas de tomar e destruir o Estado. Conforme o próprio Lenin (1983, p. 31), as revoluções russas de 1905 e 1917, num panorama distinto e em outras condições, não fazem senão continuar a obra da Comuna.

Vale a pena reproduzir o heroísmo dos comunardos enaltecido por Lenin

Assim, a Comuna "contentava-se por assim dizer, em substituir a máquina do Estado quebrada por uma democracia mais completa: supressão do exército permanente, elegibilidade e imovibilidade de todos os funcionários. Na realidade, ela "contentava-se", assim, em substituir obra gigantesca - certas instituições por outras instituições essencialmente diferentes. É esse, justamente, um caso de "transformação de quantidade em qualidade": a democracia, realizada tão plenamente e tão metodicamente quanto é possível sonhar-se, tornou-se proletária, de burguesa que era; o Estado (essa força destinada a oprimir uma classe)

Revista HISTEDBR On-line, Campinas, número especial, p. 210-224, abr2011 - ISSN: 1676-2584 
transformou-se numa coisa que já não é, propriamente falando, o Estado (LENIN, 1983, p. 26).

Além disso, a supressão de todas as despesas de representação, supressão de privilégios pecuniários dos funcionários e redução de todos ordenados administrativos em nível do "salário operário" tornam a Comuna de Paris uma revolução, verdadeiramente popular.

Partindo desses pressupostos, podemos afirmar que no tocante a questão da Revolução Comunista e do Estado - que estão indissociavelmente imbricadas - é preciso inverter e depois destruí a forma do Estado. Ou seja, processo que se dá do que representa a submissão da maioria por uma minoria para a submissão de uma minoria por uma maioria, em seguida, se realiza o definhamento, a extinção, a destruição de sua forma - já que, após o processo, não há antagonismos de classes.

A propósito, essa fase, essa forma que adquiri o Estado, segundo a perspectiva de Marx, Engels e Lenin, é chamada de socialismo - a fase de transição ou primeira fase da Sociedade Comunista.

Conforme Lenin (1983, p.90), na primeira fase do comunismo ainda não há possibilidade de justiça e igualdade. É necessário ainda subsistir diferenças de riquezas e diferenças injustas, no entanto, o que não poderá subsistir é a exploração do homem pelo homem, já que ninguém poderá dispor, a título de propriedade privada, dos meios de produção, das fábricas, das máquinas, da terra. A sociedade comunista, no seu início é obrigada a destruir apenas o "injusto" açambarcamento privado dos meios de produção, mas incapaz de destruir, simultaneamente, a injusta repartição dos objetos de consumo, conforme trabalho e não conforme as necessidades.

O autor ainda afirma que não só Marx leva em conta essa desigualdade inevitável, como ainda tem na ordem do dia o fato de que a socialização dos meios de produção - ou seja, não só uma produção para mas sob o controle dos trabalhadores - não suprime, por si só, os vícios de repartição e de desigualdades do "direito burguês" - que é parcialmente abolido - estabelecido conforme o trabalho. Esse mesmo direito atribui aos indivíduos à propriedade privada dos meios de produção. O socialismo faz deles propriedade comum subsiste a função de regulador, isso é, "quem não trabalha não come" (LENIN, 1983, p. 90).

É por isso que subsiste a necessidade de um Estado que, mesmo conservando a propriedade comum dos meios de produção, conserva a igualdade do trabalho e da repartição.

De fato, concordamos plenamente com Lenin, o poder de Estado decide tudo. Numa revolução a questão do poder do Estado, nas mãos de que classe esta esse poder decide toda a dinâmica da política interna e externa.

Tal premissa baseou a Revolução Russa em 1917, conforme a Carta ao Comitê Central, aos comitês de Petrogrado (atual São Petersburgo) e de Moscou do Partido Operário Social-Democrata Russo, cujo Lenin reivindicou:

Tendo obtido a maioria nos Sovietes ${ }^{6}$ de deputados operários e soldados de ambas as capitais, os bolcheviques podem e devem tomar o poder de Estado em suas mãos.

Podem, pois a maioria ativa dos elementos revolucionários do povo de ambas as capitais é suficiente para arrastar as massas, para vencer a resistência do adversário, para destruí-lo, para conquistar o poder e mantê-lo. Pois, propondo imediatamente uma paz democrática, entregando imediatamente a terra aos camponeses, restabelecendo as 
instituições e as liberdades democráticas [...] os bolcheviques formarão um governo que ninguém derrubará (LENIN, 1978a).

O militante e intelectual russo assegura a classe trabalhadora dominante como a única a tomar o Estado, invertendo e transformando sua forma em provisória e em transição, rumo à edificação de uma sociedade comunista. Lenin predica, concomitantemente, a defesa desta forma, conforme publicação no jornal político Pravda $^{7}$, em Novembro de 1917, no texto intitulado À população, que suscita

É completamente compreensível que os latifundiários e os capitalistas, os altos empregados e funcionários, estreitamente ligados à burguesia, numa palavra, todos os ricos e todos os que estão com os ricos, acolham hostilmente a nova revolução, se oponham à sua vitória, ameacem paralisar a atividade dos bancos, sabotem ou paralisem o trabalho de diferentes instituições, o obstaculizem por todos os meios, o entravem direta ou indiretamente. Todo o operário consciente compreendeu perfeitamente que encontraríamos inevitavelmente tal resistência, toda a imprensa partidária dos bolcheviques o assinalou muitas vezes. As classes trabalhadoras não se assustarão um só instante com essa resistência, nem cederão minimamente Perante as ameaças e as greves dos partidários da burguesia.

A maioria do povo está por nós. A maioria dos trabalhadores e dos oprimidos de todo o mundo está por nós. A nossa causa é a causa da justiça. A nossa vitória está assegurada.

A resistência dos capitalistas e dos altos empregados será quebrada. Nenhuma pessoa será privada por nós dos seus bens sem uma lei especial do Estado sobre a nacionalização dos bancos e dos consórcios. Esta lei está a ser preparada. Nenhum trabalhador perderá um só copeque ${ }^{8}$; pelo contrário, ser-lhe-á prestada ajuda. O governo não quer introduzir quaisquer outras medidas que não sejam o mais rigoroso registro e controle, que não seja a cobrança sem ocultação dos impostos anteriormente estabelecidos.

Em nome destas justas reivindicações, a imensa maioria do povo uniu-se em torno do governo provisório operário e camponês.

Camaradas trabalhadores! Lembrai-vos que vós próprios dirigis agora o Estado. Ninguém vos ajudará se vós próprios não vos unirdes e não tomardes nas vossas mãos todos os assuntos do Estado. Os vossos Sovietes são a partir de agora órgãos do poder de Estado, órgãos plenipotenciários ${ }^{9}$ e decisivos (LENIN, 1978b).

Portanto, se faz necessária a questão: qual é a principal arma que a classe trabalhadora deve se apropriar que a permita revolucionar e lutar por uma sociedade sem classes? O marxismo-leninismo ${ }^{10}$ é a arma fundamental para tal feito.

Neste horizonte, a constituição de uma sociedade comunista esta diretamente conectada as bases materiais da sociedade. Partindo dos homens reais, mais precisamente, do modo como os homens produzem sua existência. Ou seja, o homem como demiurgo da sua história. Assim, fundamentando-se na obra A Ideologia Alemã de Marx e Engels (1998, p.10), as premissas de que se deve partir são bases reais que só podemos abstrair na imaginação, são os indivíduos reais, sua ação e suas condições materiais de existência, tanto as que eles já encontram prontas, como aquelas engendradas de sua própria ação. Essas bases são verificáveis por via puramente empírica. Assim, ao adaptar a natureza à 
sua existência, ou seja, ao produzirem seus meios de existência, os homens produzem sua própria vida material (MARX; ENGELS, 1998 p. 10-11).

Indispensável dizer que, nos pautamos no método materialista dialético da história - método concebido por Marx e Engels e ampliado por Lenin. Justifica-se a necessidade deste método como único capaz de superar as concepções de mundo idealistas positivismo e fenomenologia - e singular quanto a colocar na ordem do dia a classe proletária, a classe trabalhadora com protagonista da sua história.

O materialismo dialético da história se baseia em bases reais, no modo como os homens produzem sua existência, recuperando a história como ciência e o princípio da contradição da dialética.

Nesse sentido, Marx e Engels, esquadrinham, de modo rigoroso e radical, o modo de produção capitalista - circunscrito desde as primeiras civilizações comunais, feudais, a transição às formações pré-capitalistas até final do século XIX, e advogam sua superação pela edificação do comunismo - em sua totalidade: suas relações filosóficas, políticas, econômicas, sociais e, inclusive, sua superação. Esses revolucionários investigando as formações humanas, a produção, as relações de produção, de troca e as forças produtivas, reivindicam o conceito - cujo motor da história - de luta de classes entre: capitalistas e trabalhadores.

Desta forma, Lenin defende veemente o método marxista como onipotente e exato. Um método completo e harmonioso, que dá aos homens uma concepção, integral do mundo, inconciliável com toda a superstição, com toda a reação, com toda a defesa da opressão burguesa. O marxismo é o sucessor legítimo do que de melhor criou a humanidade no século XIX: a filosofia alemã, a economia política inglesa e o socialismo francês (LENIN, 1913).

Lenin (1981a, p. 356) ainda acrescenta que o marxismo é a único método que compara os fatos políticos, jurídicos, sociais, habituais e outros com a economia, com o sistema das relações de produção, com interesses de classe que inevitavelmente se formam no terreno de todas as relações sociais antagônicas.

A teoria de Marx e Engels desvela

todas as formas de antagonismo e exploração da sociedade moderna, estuda sua evolução, demonstra seu caráter transitório, assim como a inevitabilidade de sua conversão noutra forma distinta e serve assim ao proletariado para que este ponha fim o mais antes possível e com a maior facilidade possível a toda exploração (LENIN, 1981a, p. 356).

O materialismo dialético e histórico é a única concepção capaz de superar e trocar as bases históricas da atual sociedade. Na discussão acerca da filosofia e ciência inseridas nesta concepção, em uma entrevista - A filosofia como uma arma revolucionária - Louis Althusser (2007), advoga que a teoria marxista-leninista abrange uma ciência (o materialismo histórico) e uma filosofia (o materialismo dialético) portanto, uma das armas teóricas indispensáveis para a luta de classe. Assim, os militantes comunistas devem assimilar e aplicar esses princípios: ciência e filosofia. A revolução proletária, na defesa dessa perspectiva, precisa de militantes que são tanto cientistas - materialistas históricos quanto filósofos - materialistas dialéticos (ALTHUSSER, 2007).

Nesse sentido, atualizar, esquadrinhar, reivindicar, colocar em prática as obras de Marx, Engels, Lenin enfim, toda perspectiva marxista-leninista é estratégia principal dos trabalhadores intelectuais e militantes que lutam pela sociedade comunista. 


\section{Acerca da educação comunista}

Acertadas as palavras e fundamentos de ordem filosófica, econômica e social sobre o modo capitalista de produção da existência e as premissas para sua superação, podemos desenvolver a questão da educação - que apesar de não ser tema central nas obras de Lenin, é expressa com uma relevância crucial.

Fundamentando-se nas bases do método materialista dialético da história - do qual não abandona -, o autor desenvolve a crítica, ao modo capitalista de produção, e conseqüentemente, a própria educação burguesa, capitalista - já que a educação é determinada, em última instância, pelo modo de produção de existência, da vida material.

Desde meados do século XIX, Marx e Engels iniciam esse mesmo trabalho, de forma inédita até aquele contexto histórico (século XIX, em plena celebração da revolução industrial), a questão das condições de trabalho e ensino dos filhos dos trabalhadores nas indústrias. Os autores denunciam que não se poderia imaginar melhor método de embrutecimento que o trabalho na fábrica, e se apesar de tudo os operários não só salvaram sua inteligência, mas, simultaneamente, a desenvolveram e a aguçaram mais do que os outros, isso apenas foi possível pela revolta contra a sorte e contra a burguesia. Essa revolta é o único pensamento e sentimento que o trabalho lhes permite. E se esta indignação contra a burguesia não se torna o sentimento predominante entre eles, a consequiência inevitável é o alcoolismo e tudo o que habitualmente se chama de imoralidade (MARX; ENGELS, 1983, p. 25).

Os autores predicam que não se pode descartar a condição de que a superação da propriedade privada é a emancipação plena de todos os sentidos e qualidades humanas; porém, é esta emancipação, precisamente, porque todos estes sentidos e qualidades tornaram-se humanos, tendo no sentido objetivo quanto subjetivo (MARX; ENGELS, 1983, p. 34). E ainda acrescentam que

\footnotetext{
No sei o da produção material, o trabalho não pode se emancipar a não ser que: $\left(1^{\circ}\right)$ seu conteúdo social esteja assegurado; $\left(2^{\circ}\right)$ revista-se de um caráter científico e apareça diretamente com trabalho genial; [...] deixar de ser esforço do homem, simples força natural em estado bruto que sofreu um adestramento determinado para chegar a ser atividade do sujeito que regula todas as forças da natureza no seio do processo de produção (MARX; ENGELS, 1983, p. 34)
}

De fato, no próprio seio da produção material capitalista, sustentada pela exploração da maioria pela minoria (parasitária), se situa a contradição que leva a revolução, e nela uma arma essencial: a educação. De uma educação dualista, distinta entre capitalista e trabalhador, que é sistematizada para separar do último seu trabalho de sua produção - ou seja, separação entre trabalho e produção, produtor e produção, o homem de sua condição básica e fundamental de homem - para uma educação que revolucione esta contradição, que a supere no grau mais elevado da emancipação humana. Em nossa análise, esta se chama educação comunista no sentido mais puro da palavra.

Marx e Engels (1983, p. 60) deixam evidente que é preciso combinar trabalho produtivo, socialmente útil, com a educação. Estabelecendo, para esta, três premissas essenciais: (I) educação intelectual, (II) educação corporal - educação física - e a (III) educação para o trabalho - educação politécnica -, isso é, os princípios gerais e de caráter científico de todo processo de produção e o manejo de ferramentas elementares dos diversos ramos industriais. Enfim, uma educação humana que articule filosofia, ciência e produção baseada no trabalho. 
No raiar do século XX a Rússia era um país economicamente atrasado. Uma nação de extensões continentais, agrária, com uma população preponderantemente camponesa e miserável explorada por um regime czarista que somente teve seu término com a revolução russa (ou bolchevique ${ }^{11}$ ) de 1917 - ou seja, um universo de contradições extremamente distinto da constelação de fundamentos arquitetadas por Marx e Engels sobre a revolução do proletariado. Podemos dizer que Lenin deu forma à teoria revolucionária de Marx e Engels, tendo que colocar na ordem do dia a revolução proletária num país que não havia 'passado' pelos moldes da revolução burguesa e cuja maior parte de agentes revolucionários não eram operários e sim camponeses.

Desta forma, de que se trata a educação comunista dos trabalhadores russos? $O$ quê e como deveriam aprender? Como deveria ser o ensino, a educação e a instrução dos trabalhadores? Onde deve residir o centro de gravidade desta educação? E ainda: o que deveria ser tomado da velha ciência burguesa?

$\mathrm{O}$ fato era que governo bolchevique situava-se num contexto deixado pela burguesia de total descaso acerca do sistema educacional voltada a classe trabalhadora, que se manifesta de modo bastante evidente, por exemplo, acerca das condições de trabalho do corpo docente: os professores das escolas públicas sobreviviam com baixos salários e em condições de absoluta miséria - condenados a fome (LENIN, 1984a, p. 211).

Outro exemplo a ser sublinhado é a denúncia de Krupskaya (LENIN, 1984b, p. 286) acerca da absurda censura em torno da política do ministério de instrução pública, quando revoga que

Nos países civilizados quase não há analfabetos. Ali se propicia a atrair o povo às escolas. Articulam-se todos os meios para organização das bibliotecas. Mas em nosso país o Ministério de Instrução (perdão!) Pública arquiteta os esforços mais desesperados e recorre à medidas políticas mais escandalosas para dificultar a instrução, para impedir que o povo aprenda! Em nosso país, o ministro tem destruído as bibliotecas escolares! Os países cultos não possuem regras especiais contra as bibliotecas e também nenhuma medida tão abominável como esta censura. [...] Tudo isso constitui uma escandalosa política de obscurantismo em respeito ao povo, uma escandalosa política dos latifundiários, que desejam o emburrecimento do país.

Além destas condições era preciso lutar contra as velhas ilusões burguesas inculcadas pelo reacionarismo dos professores liberais. No texto Um professor liberal opina sobre a igualdade, Lenin critica a atitude dos professores liberais quando estes tentam refutar a luta do socialismo a respeito da igualdade, lecionando que seria impossível uma sociedade humana exclusivamente igualitária, confundindo igualdade de direitos, igualdade de forças, igualdade econômica, social e política com igualdade acerca de atitudes físicas e mentais. Segundo Lenin (1984c, p. 385), esses professores prostituem a ciência a favor do capital usando argumentos mais absurdos, estúpidos e desavergonhados.

Para superar esse contexto era fundamental (é fundamental) educar a toda classe de trabalhadores com a finalidade que desempenhem o papel de combatentes para se emancipar de qualquer opressão de toda humanidade, e nessas mesmas águas, era preciso (é preciso) instruir constantemente a classe trabalhadora não somente com livros mas também mediante a participação na luta diária e prática - na vida política. - eis esse um elemento pedagógico fundamental (LENIN, 1982, p. 372).

Também cabe destacar aqui, elementos da brilhante sistematização da educação comunista coordenada por Krupskaya - idéias bastante afinadas com as de Lenin - cuja 
educação comunista deveria orientar a desenvolver as atitudes de todos os estudantes, a elevar a sua atividade, sua consciência, fortalecer sua personalidade e individualidade, buscando fazer dos estudantes pessoas multifacetadas, versáteis sem contrapor sua individualidade a coletividade (KRUPSKAYA, S/d, p. 89-90). Krupskaya também coloca em pauta a necessidade da mesma educação para ambos os sexos, a necessidade da valoração do trabalho socialmente útil e o espírito de unidade e fraternidade de todos os trabalhadores.

Ainda nos textos de Krupskaya (S/d, p. 163-165) é possível sublinhar a necessidade do trabalho socialmente útil articulado a escola, que permita: a valorização tanto do trabalho manual como do trabalho intelectual, a distinção entre a instrução politécnica fundamentos da ciência incorporados pela produção em seu conjunto - e instrução profissional - o domínio da técnica e dos meios de produção e aumentar as relações entre estudantes e operários. Por exemplo, essa articulação fica bem clara na questão das escolas nas áreas rurais (fazendas-escolas e escolas correcionais), cujo planejamento consistia em sistematizar o período de aulas articulado com trabalhos artesanais e cooperativas agrícolas. Onde o custo da instrução seria suprimido pelo trabalho dos operários, complementado pelos alunos, funcionários e professores. Segundo Lenin (1981b, p. 66), estas cooperativas agrícolas seriam os primeiros passos para socialização popular da produção, com parte de um novo caminho para ludibriar as peripécias do capitalismo.

Nesse sentido, é preciso retomar a questão: de que se trata a educação comunista?

Lênin (1977, p. 203), falando à União da Juventude Comunista em 1920, afirmou

que

[...] o quê e como aprender? E neste problema o essencial é que, com a transformação da velha sociedade capitalista, o ensino, a educação e a instrução das novas gerações, destinadas a criar a sociedade comunista, não podem seguir sendo o que eram. Pois bem, o ensino, a educação e a instrução da juventude devem partir dos materiais que nos têm legado a antiga sociedade. Não podemos edificar o comunismo se não é a partir da soma de conhecimentos, organizações e instituições, com o acervo de forças e meios e forças humanas que temos herdado da velha sociedade. Só transformando radicalmente o ensino, a organização e a educação da juventude, conseguiremos que os resultados dos esforços da jovem geração seja a criação de uma sociedade que não se pareça à antiga (a burguesa), a saber, da sociedade comunista.

Devemos dirigir todos os esforços para este fim. tal como Marx e Engels se apoiavam na sólida base de conhecimentos humanos adquiridos sob o capitalismo. Ao estudar as leis de desenvolvimento da sociedade humana, os autores compreenderam o caráter inevitável do desenvolvimento do capitalismo, que conduz ao comunismo, o demonstrou baseando-se exclusivamente no estudo mais exato, detalhado e profundo de dita sociedade capitalista, assimilando plenamente tudo o que a ciência havia dado até então. Tudo o que havia criado a sociedade humana, o analisou Marx e Engels com espírito crítico, sem desdenhar um só ponto. Tudo o que havia criado o pensamento humano, o analisou, o submeteu a crítica, o comprovou no movimento operário (LENIN 1977, p. 206).

No entanto, é preciso que evitar o equivoco de pensar que basta aprender as consignas comunistas, as conclusões da ciência comunista, sem assimilar a soma de conhecimentos dos quais é conseqüência o próprio comunismo. A cultura proletária 
tem que ser o desenvolvimento lógico do acervo de conhecimentos conquistados pela humanidade sob o jugo da sociedade capitalista, da sociedade dos latifundiários e burocratas. Estes são os caminhos e as sendas que têm conduzido e continuam conduzindo até à cultura proletária, do mesmo modo que a economia política, transformada por Marx [e Engels], nos têm mostrado aonde deve chegar a sociedade humana, nos têm indicado o passo na luta de classes, ao começo da revolução proletária (LENIN, 1977, p. 207).

O ensino, a educação e instrução dos trabalhadores devem ser baseados, distintamente do adestramento imposto pela sociedade burguesa contra a vontade da maioria, na disciplina consciente dos trabalhadores urbanos e rurais unem a decisão, a capacidade e o desejo de unificar e organizar suas forças para a luta de classes, com o fim de criar, com milhões e dezenas de milhões de vontades isoladas, divididas, dispersas cada vez mais pelo capital, numa vontade única, porque sem ela seremos inevitavelmente vencidos (LENIN, 1977, p. 208). Só ligando cada passo de sua instrução, de sua educação e de sua formação à luta incessante dos proletários e dos trabalhadores contra sociedade dos exploradores é possível a edificação de uma sociedade sem classes. Ou seja,

Só ligando indissoluvelmente e em todo momento a instrução, a educação e a formação dos estudantes à luta de todos os trabalhadores contra os exploradores.

[...] E é preciso que a União de Juventudes Comunistas unifique sua formação, sua instrução e educação ao trabalho dos operários e dos camponeses e que não se encerre em suas escolas ou se limite a ler os livros ou os folhetos comunistas. Só trabalhando com os operários e camponeses, se pode chegar a ser um verdadeiro comunista (LENIN, 1977, p. 216-217). política.

Sem dúvida a educação comunista deve ser sustentada por uma constante prática

Esta educação com dimensão política é a base para formação de uma consciência socialista, de uma consciência comunista, que deve conduzir a classe trabalhadora a erradicar o espírito burguês da produção de sua existência. A propósito, concordamos com Lenin (1981c, p. 370), quando o revolucionário defendia nas As tarefas da juventude revolucionária que

[...] certa parte dos estudantes querem formar uma visão de mundo socialista concreta e abrangente. O objetivo final deste trabalho preparatório não pode ser outro - para os estudantes que desejam participar de uma maneira prática do movimento revolucionário - que a escolha consciente e definitiva de uma das perspectivas cristalizadas atualmente nos meios revolucionários. Aqueles que protestam contra esta escolha por razões de unificação ideológica dos alunos, em sua revolução em geral e etc, não fazem outra coisa que refutar a consciência socialista, propugnam na verdade, apenas o vazio ideológico. A classificação política de todos os estudantes deve refletir para reforçar as organizações políticas da sociedade como um todo, e é dever de todos socialistas se esforçarem para obter uma demarcação mais consciente e conseqüente possível de grupos politicamente heterogêneos. [...] O rompimento dos estudantes socialdemocratas com os revolucionários e os políticos de todas as demais tendências não significa de nenhuma maneira o 
rompimento das organizações estudantis gerais e educativas, pelo contrário, só permanecendo o ponto de vista de um programa plenamente definido se pode e se deve trabalhar entre os mais vastos setores estudantis para ampliar os horizontes acadêmicos e propagar o socialismo científico, quer dizer, o marxismo.

É tarefa de todo educador comunista lutar para que a escola não se situe a margem da dimensão política. No Brasil, onde a história da humanidade foi, e ainda é, furtada da classe trabalhadora, não será possível erradicar o analfabetismo e a fome sem uma educação política, sem uma consciência socialista. A separação da escola da política ou mesmo da vida na escola capitalista é premissa fundamental do projeto do modo de produção capitalista de existência. É um mecanismo de proteção do modo de produção capitalista que cada vez mais fragmenta a totalidade, e quando, via lutas ferrenhas, a classe trabalhadora conquista espaços, os capitalistas de todos os setores do planeta intensificam a exploração ou mesmo reforçam as relações de subordinação e o enaltecimento do espírito burguês, dos pressupostos liberais.

Nesta perspectiva, é necessário inverte a ordem, a educação deve estar a serviço da classe trabalhadora e não da capitalista. Assim, concordamos com o professor Máuri de Carvalho referente a seu estudo acerca das contribuições de Lenin para a pedagogia comunista, na sociedade brasileira e mundial, conforme pressupostos:

(i) A reforma pedagógica. Entretanto, na perspectiva marxista-leninista nenhuma reforma pedagógica, verdadeiramente popular e democrática, será efetivada antes que a classe - sujeito-objeto do processo histórico interessada no seu concurso assuma controle dos meios de instrumentos de produção material e intelectual.

(ii) A educação política. Diferente da educação capitalista ela contempla especialmente os interesses da classe operária e dos camponeses pobres. Essa educação é indispensável para que a classe social dominada retire o mando dos meios e instrumentos de produção, do Estado e seus aparelhos ideológicos e repressivos, das mãos da burguesia, assumindo-os para implementar o desmanche do velho sistema, pari passu, com a construção de uma nova sociedade.

(iii) A prática social do "educador comunista" laborando no controvertido caminho da universidade pública, não pode ficar condicionado aos estritos limites impostos pela Nomenklatura acadêmica, nos quais a ordem burguesa põe por objetivo sinecuras e prebendas.

(iv) A transformação estrutural da escola passa, necessariamente, pela transformação estrutural da sociedade capitalista. Contudo, deve ficar claro que a escola é um importante espaço na luta pela solução das contradições materiais e sociais imanentes ao capitalismo. Com efeito, a ambigüidade permite afirmar não ser a escola apenas mais uma época, mas também lócus onde se trava a luta de classes e idéias heréticas circulam (FREITAS, 2005, p.110-111).

$\mathrm{O}$ autor ainda acrescenta que o processo educativo só se concretiza a partir do conhecimento científico e da militância organizada (FREITAS, 2005, p. 111). Ou seja, a educação deve servir a classe trabalhadora, transmitindo conhecimentos de base científica, econômica, filosófica, política e social. Assim sendo, a compreensão do modo de produção capitalista de existência como um todo, em sua totalidade é a chave para sua superação e edificação de seu antagonismo: o modo de produção comunista da existência. 


\section{À guisa de conclusão}

No capítulo 3 de A era dos impérios, de mesmo título, de Hobsbawm inicia-se afirmando ser muito provável que uma economia mundial cujo ritmo era determinado por seu núcleo capitalista desenvolvido ou em desenvolvimento, se tornasse um mundo no qual os "avançados" dominariam os "atrasados"; em resumo, num mundo de império, no qual as duas maiores regiões do mundo (África e Pacífico) foram, para fins práticos, divididas (HOBSBAWM, 2003, p. 87 e 89). O autor sublinha ser "perfeitamente claro" que estas regiões fossem economicamente dependentes do mundo desenvolvido. Esta divisão do mundo é considerada como "a expressão mais espetacular da crescente divisão do planeta em fortes e fracos, em 'avançados' e 'atrasados"' (HOBSBAWM, 2003, p. 90-91). O autor vai demonstrar como, na análise leninista, esta divisão configura-se na maior expressão da expansão do capitalismo, o que é rebatido pelos opositores do marxismo, levando ao obscurecimento do tema (HOBSBAWM, 2003, p.93).

É neste contexto que as análises, o trabalho, a obra de Lenin são extremamente atuais, extremamente presentes. Com efeito, ao repetir e desenvolver seu trabalho, apesar do fracasso do socialismo existente, não basta admitir os compromissos em geral para que desapareça completamente a linha divisória entre o capitalismo e o comunismo. É preciso o estudo prolongado, a educação, a instrução e a experiência política e prática.

Para esse propósito, apropriando-se do método materialista dialético da história como guia para a incorporação crítica dos conhecimentos (filosóficos, econômicos, científicos, políticos e sociais) historicamente acumulados pela humanidade (sob a sociedade capitalista) articulados aos estudos das experiências revolucionárias - Comuna de Paris, a revolução russa e soviética, chinesa, cubana -, consiste num legado de suma relevância para a classe trabalhadora tomar sua história - compreender as contradições do capital e o suprimir.

Em suma, é necessário enfatizar: de que se trata a educação comunista?

Trata-se, em primeiro lugar, de que não basta uma simples indicação, abstrata, do que é a cultura proletária, a cultura comunista. É preciso saber concretamente assimilar a soma dos conhecimentos adquiridos pela humanidade sob o jugo do capitalismo - se apropriar de toda ciência até então desenvolvida. E em segundo lugar, a tarefa da educação comunista, diferentemente da capitalista, deve ser voltada para todos trabalhadores (urbanos e rurais) - uma tarefa que não se restringe aos muros da escola, ou de um partido, governo ou instituição.

Para Lenin (1982, p. 373) o Partido Operário Social Democrata Russo deveria ser uma grande escola que tinha como necessidade ensinar o abc, de transmitir os fundamentos do saber e o hábito, a prática de pensar por conta própria.

Concordamos que esta é premissa básica para educação voltada à classe trabalhadora, especialmente, a brasileira: transmitir fundamentos para que pensem por conta própria!

\section{Bibliografias}

ALTHUSSER, L. A filosofia como uma arma revolucionária. Entrevistadora concedida a: Maria Antonietta Macciocchi publicada em L'Unità, 1968. Tradução de Gabriel Zerbetto Vera, 2007. Disponível em < http://marxists.anu.edu.au/portugues/althusser/1968/02/filosofia.htm>. Acesso em: $10 \mathrm{dez}$. 2010. 
FREITAS, Francisco Máuri de Carvalho. Lenin, educação e consciência socialista. In: LOMBARDI, José Claudinei; SAVIANI, Dermeval. (orgs.) Marxismo e Educação: debates contemporâneos. Campinas: Autores Associados: Histedbr, 2005. p. 95-122.

HOBSBAWM, Eric J. A era dos impérios: 1875-1914. 8. ed. São Paulo: Paz e Terra, 2003

KRUPSKAIA, N. Diferencia entre la instrucción profesional y la politécnica. In: KRUPSKAIA, N. Acerca de la Educacion Comunista - Articulos y Discursos. Traduzido do russo por V. Sanchez Esteban. Moscou. Ediciones en Lenguas Extranjeras. S/d. p. 163-165.

KRUPSKAIA, N. El movimiento de pioneros como problema pedagógico. In: KRUPSKAIA, N. Acerca de la Educacion Comunista - Articulos y Discursos. Traduzido do russo por V. Sanchez Esteban. Moscou. Ediciones en Lenguas Extranjeras. S/d. p. 88-92.

LENIN, V. I. Adição ao artigo de N. K. Krúpskaia 'em torno à política do Ministério de Instrução Pública. In: LENIN, V. I. Obras Completas. 5. ed. Em Cinqüenta e Cinco Tomos. Moscou: Progresso, 1984b, t. 24. p. 286.

LENIN, V. I. A miséria dos mestres de escolas públicas. In: LENIN, V. I Obras Completas. 5. ed. Em Cinqüenta e Cinco Tomos. Moscou: Progresso, 1984a, t. 24. p. 209211.

LENIN, V. I. À População. Tradução por Edições Avante. In: LENIN, V. I. Obras Escolhidas em Três Tomos. Moscou: Progresso, 1978b. t. 35, p. 65-67. Disponível em < http://www.marxists.org/portugues/lenin/1917/11/19.htm>. Acesso em: $10 \mathrm{dez} .2010$.

LENIN, V. I. As fazendas-escolas e as escolas correcionais. In: LENIN, V. I. Obras Completas. 5. ed. Em Cinqüenta e Cinco Tomos. Moscou: Progresso, 1981b, t. 2. p. 6073.

LENIN, V. I. As tarefas da juventude revolucionária. In: LENIN, V. I. Obras completas. 5. ed. Em Cinqüenta e Cinco Tomos. Moscou: Progresso, 1981c. t. 7. p. 356-374.

LENIN, V. I. As três fontes e as três partes constitutivas do marxismo. Tradução por Edições Avante. In: LENIN, V. I. Obras Completas. 5 ed. Moscou: Progresso, 1913. t. 23, p. 40-48. Disponível em < http://www.marxists.org/portugues/lenin/1913/03/tresfont.htm>. Acesso em: 10 dez. 2010.

LENIN, V. I. Confusão entre pedagogia e política. In: LENIN, V. I. Obras completas. 5. ed. Em Cinqüenta e Cinco Tomos. Moscou: Progresso, 1982. t. 10. p. 370-373.

LENIN, V. I. O Estado e a Revolução: O que ensina o marxismo sobre o Estado e o papel do proletariado na Revolução. São Paulo: Hucitec, 1983.

LENIN, V. I. O imperialismo: fase superior do capitalismo. São Paulo: Centauro, 2002.

LENIN, V. I. Os Bolcheviques devem tomar o poder. Tradução por Edições Avante. In: LENIN, V. I. Obras Escolhidas em Três Tomos. Moscou: Progresso, 1978a. t. 2, p. 306307. Disponível em <http://www.marxists.org/portugues/lenin/1917/09/14.htm>. Acesso em: 10 dez. 2010.

LENIN, V. I. Quem são os ‘Amigos do povo’ e como Lutam Contra os Social-democratas? In: LENIN, V. I. Obras Completas. $5^{\text {a }}$ Edição em Cinqüenta e Cinco Tomos. Moscou: Progresso, 1981a, t. 1.

Revista HISTEDBR On-line, Campinas, número especial, p. 210-224, abr2011 - ISSN: 1676-2584 
LENIN, V. I. Tarefas das organizações juvenis. In: LENIN, V. I. Obras Escolhidas Em Doze Volumes. Moscou: Progresso, 1977. v. 11. p. 203-220.

LENIN, V. I. Um professor liberal opina sobre a igualdade. In: LENIN, V. I. Obras Completas. 5. ed. Em Cinquienta e Cinco Tomos. Moscou: Progresso, 1984c, t. 24.

MARX, K.; ENGELS, F. A Ideologia Alemã (I - Feuerbach). Tradução de Luis Claudio e Costa. São Paulo: Martins Fontes, 1998.

MARX K.; ENGELS F. Textos sobre educação e ensino. São Paulo: Editora Moraes, 1983.

Notas:

${ }^{1}$ Artigo baseado na avaliação da disciplina do programa de pós-graduação em Educação da Universidade Estadual de Campinas - História Geral da Educação e da Pedagogia - ministrada Professor Dr. José Claudinei Lombardi.

${ }^{2}$ Graduado em Educação Física pela Universidade Estadual de Londrina e estudante do programa de pós graduação da mesma instituição.

${ }^{3}$ Um levantamento bibliográfico a respeito via Plataforma Lattes (banco de currículos e grupos de pesquisa do CNPq - Órgão responsável pelo fomento do desenvolvimento científico e tecnológico brasileiro criado em 1951 pela lei 1.310), na base doutores e demais pesquisadores entre as datas 23/11/2010 as $9 \mathrm{~h} 37 \mathrm{e}$ 25/11/2010 as 22h14, apresentou que: de 277 resultados disponíveis com a palavra-chave lenin, foram encontrados 190 autores e desses autores, foram encontrados somente 10 (dez) trabalhos cujo tema central se referia a educação.

${ }^{4}$ Associações financeiras que realizam a fusão de várias empresas em uma única.

${ }^{5}$ Após proclamação da Terceira República Conservadora, milhares de trabalhadores de Paris, França, insatisfeitos com sua miséria, revoltaram-se numa grande rebelião socialista, assumindo o controle da cidade e organizando um governo popular: a Comuna de Paris.

${ }^{6}$ Os Sovietes surgiram em 1905 como órgãos da insurreição armada, concebidos pela criatividade revolucionária das massas populares, como expressão da criação do povo, como manifestação da iniciativa do povo - as organizações mais representativas e de massas que unem em si as características próprias de órgãos estatais e de organizações sociais; a encarnação mais completa do caráter democrático do Estado Socialista.

${ }^{7}$ Pravda (A Verdade) periódico bolchevique legal que começou a circular em Petersburgo no dia 22 de abril de 1912.

${ }^{8}$ Moeda divisionária da Comunidade dos Estados Independentes - países que constituíam a União das Repúblicas Socialistas Soviéticas, do valor de 1/100 do rublo.

${ }^{9}$ Plenipotenciário (derivado de plenipotência, que vem do latim plenipotens) se diz daquele que tem todos os poderes.

${ }^{10} \mathrm{O}$ termo leninista, derivado leninismo (doravante do marxismo-leninismo) é o conjunto de idéias lavradas por Lenin enquanto práxis, crítica e revolucionária, voltada do poder pelo proletariado, como a participação dos camponeses pobres, via expropriação dos expropriados, em direção à construção do socialismo e da sociedade comunista (FREITAS, 2005, p.100).

${ }^{11}$ Em 1903 o Partido Operário Social Democrata Russo, perseguido violentamente pela polícia czarista desde 1898, foi dividido em: Mencheviques (minoria), que, em linhas gerais, defendiam o amadurecimento do capitalismo, para então buscar o socialismo; e Bolcheviques (maioria) eram a esquerda majoritária do partido, que defendiam a implementação integral do programa socialista de liderança proletária centralizada, liderados por Lenin e apoiados pelos sovietes.

Recebido em: $\quad$ 14/10/10

Aprovado em: 24/03/11 